
\title{
3 Research Square \\ The Implications of Treatment Delays In Adjuvant Therapy For Resected Cholangiocarcinoma Patients
}

\section{Matthew Parsons}

University of Utah Health Huntsman Cancer Institute

Shane Lloyd

University of Utah Health Huntsman Cancer Institute

Skyler Johnson

University of Utah Health Huntsman Cancer Institute

Courtney Scaife

University of Utah Health Huntsman Cancer Institute

Heloisa Soares

University of Utah Health

Rebecca Kim

University of Utah Health Huntsman Cancer Institute

Robin Kim

University of Utah Health Huntsman Cancer Institute Ignacio Garrido-Laguna

University of Utah Health Huntsman Cancer Institute

Randa Tao ( $\square$ randa.tao@hci.utah.edu )

University of Utah Health Huntsman Cancer Institute https://orcid.org/0000-0001-9379-4732

\section{Research Article}

Keywords: Cholangiocarcinoma, biliary, radiation, adjuvant, treatment delay

Posted Date: July 20th, 2021

DOI: https://doi.org/10.21203/rs.3.rs-683120/v1

License: (c) (1) This work is licensed under a Creative Commons Attribution 4.0 International License.

Read Full License 


\section{Abstract}

Purpose: To understand factors associated with timing of adjuvant therapy for cholangiocarcinoma and the impact of delays on overall survival (OS).

Methods: Data from the National Cancer Database (NCDB) for patients with non-metastatic bile duct cancer from 2004 to 2015 were analyzed. Patients were included only if they underwent surgery and adjuvant chemotherapy and/or radiotherapy (RT). Patients who underwent neoadjuvant or palliative treatments were excluded. Pearson's chi-squared test and multivariate logistic regression analyses were used to assess the distribution of demographic, clinical, and treatment factors. After propensity-score matching with inverse probability of treatment weighting, OS was compared between patients initiating therapy past various time points using Kaplan Meier analyses and doubly-robust estimation with multivariate Cox proportional hazards modeling.

Results: In total, 7,733 of 17,363 (45\%) patients underwent adjuvant treatment. The median time to adjuvant therapy initiation was 59 days (interquartile range 45-78 days). Age over 65, black and Hispanic race, and treatment with RT alone were associated with later initiation of adjuvant treatment. Patients with larger tumors and high grade disease were more likely to initiate treatment early. After propensity score weighting, there was an OS decrement to initiation of treatment beyond the median of 59 days after surgery.

Conclusions: We identified characteristics that are related to the timing of adjuvant therapy in patients with biliary cancers. There was an OS decrement associated with delays beyond the median time point of 59 days. This finding may be especially relevant given the treatment delays seen as a result of COVID-19.

\section{Introduction}

Cholangiocarcinoma (CCA) is comprised of a diverse set of epithelial tumors with features of cholangiocyte differentiation. ${ }^{1-3}$ It is the most common biliary malignancy and the incidence has progressively increased over the last 40 years. ${ }^{3,4}$ These tumors are subdivided based on anatomical location as intrahepatic (iCCA), perihilar (pCCA), or extrahepatic/distal (dCCA) ${ }^{3,5}$ Importantly, these subsets of CCA vary not only by location, but may also vary by molecular characteristics, biology, and treatment options. ${ }^{1,6}$ CCAs are aggressive tumors and the majority of patients have advanced disease at diagnosis. ${ }^{7}$ As a result, prognosis for CCA is poor with a median survival of 24 months from diagnosis. Surgery is considered the only curative therapy for patients with early stage, resectable disease. ${ }^{8}$

The mainstay of therapy for all subtypes of early stage CCA is surgery, provided that patients are surgical candidates and have resectable disease. ${ }^{9}$ The roles of adjuvant chemotherapy (CT) and radiation therapy (RT) are evolving and are dependent on the extent of surgical resection, lymph node status, and tumor location. ${ }^{10}$ 
According to NCCN guidelines, adjuvant therapy is standard of care in patients with positive margins or lymph nodes, and should be strongly considered in patients with negative margins or lymph nodes given the aggressive nature of the disease. ${ }^{11}$ Support for the utilization of adjuvant treatment comes from two prospective trials, the SWOG 0809 and BILCAP studies. The SWOG study was a single arm phase II multicenter study that demonstrated promising efficacy and tolerable side effect profiles for adjuvant chemotherapy followed by chemoradiation therapy. The BILCAP study was a phase III randomized trial that evaluated the role of adjuvant capecitabine. The study primary endpoint was overall survival. The study showed a trend towards improved survival in the intention to treat analysis. The survival improvement was confirmed in a prespecified per-protocol analysis (53 vs 36 months, $\mathrm{HR}=0.75,95 \% \mathrm{Cl}$ $0.58-0.97)^{12,13}$

The role of timing of adjuvant therapy in the setting of CCA has not yet been studied. The BILCAP study initially required patients to start adjuvant therapy within 8 weeks of surgery, however the protocol was later adjusted to allow initiation within 12 weeks and later extended again to 16 weeks. ${ }^{13}$ The SWOG trial required enrollment within 8 weeks. However, the impact of these time points has not been formally analyzed. With the emergence of COVID-19 delaying therapy for a number of oncology patients, ${ }^{14-16}$ we set out to evaluate factors associated with delays in the initiation of adjuvant therapy for CCA as well as the impact of these delays on survival outcomes.

\section{Materials And Methods}

Patient data was obtained from the National Cancer Database (NCDB), a joint project of the Commission on Cancer ( $\mathrm{CoC}$ ) of the American College of Surgeons and the American Cancer Society, which includes data from approximately 1,500 hospitals and clinics in the United States and its territories. This database captures nearly $70 \%$ of new cancer diagnoses made in the United States. ${ }^{17}$ The CoC NCDB and the hospitals participating in the COC NCDB are the source of the de-identified data used in this study; these data have not been verified and the $\mathrm{CoC}$ is not responsible for the statistical validity of the data analysis or the conclusions of the authors.

The NCDB was queried for patients diagnosed with bile duct cancer between 2004 and 2015, which yielded 92,849 patients (Fig. 1). Patients were excluded if they had metastatic disease at diagnosis (55,335 remaining), had non-invasive disease (50,548 remaining), did not undergo surgery $(21,773$ remaining), underwent neoadjuvant therapy $(20,013$ remaining), were treated with palliative intent $(19,510$ remaining), had an incompletely recorded treatment course (18,597 remaining), if death or date of the last contact occurred less than 3 months from diagnosis, and if survival time was unavailable $(17,363$ remaining).

Among patients who underwent adjuvant therapy, median and interquartile ranges (IQR) for time from surgical resection to adjuvant therapy were used to divide patients into quartiles of time to adjuvant therapy. Differences in the distribution of demographic, clinical, and treatment characteristics among groups were assessed using Pearson's chi-squared analysis. Propensity-score matching with inverse 
probability of treatment weighting (IPTW) was employed to balance covariates between patients receiving adjuvant therapy at different time points. Characteristics matched by propensity-score included age, sex, race, insurance status, income, education group, distance to care, Charlson-Deyo comorbidity score, tumor size, grade, margin status, presence of lymphovascular space invasion (LVSI), nodal status, stage, tumor location and treatment modality. Univariate and multivariate logistic regression analyses were used to assess the predictive value for delay beyond various time points. Factors with $P$-values $<.05$ on univariate analysis were included in multivariate logistic regression models. Significance was defined as any $P$-value $<.05$.

The primary outcome variable was OS. Recurrence, progression-free survival, and toxicity were unable to be assessed as these data are not recorded within the NCDB. Survival was assessed using Kaplan-Meier analyses and Cox proportional hazards modeling. Doubly-robust estimation was performed with multivariate Cox proportional hazards modeling on propensity-score matched cohorts to account for imperfect balancing of covariates. All matched variables were included within these doubly-robust multivariate models. All analyses were performed using the STATA 14.2 statistical package. ${ }^{18}$

\section{Results}

Patient demographic information is shown in Table 1. Among the 17,363 patients with non-metastatic, surgically resected CCA included in our analysis, 7,733 (45\%) underwent adjuvant therapy. This included 283 patients (4\%) treated with RT alone, 3,257 patients (42\%) treated with CT alone and 4,193 patients (54\%) treated with combination chemoradiation (CRT). Among patients treated with adjuvant therapy, the median time to initiation of therapy was 59 days (IQR 45-78 days).

Table 1. Demographic, clinical, and management characteristics of the entire patient population by time to adjuvant therapy stratified by median time to initiation. 


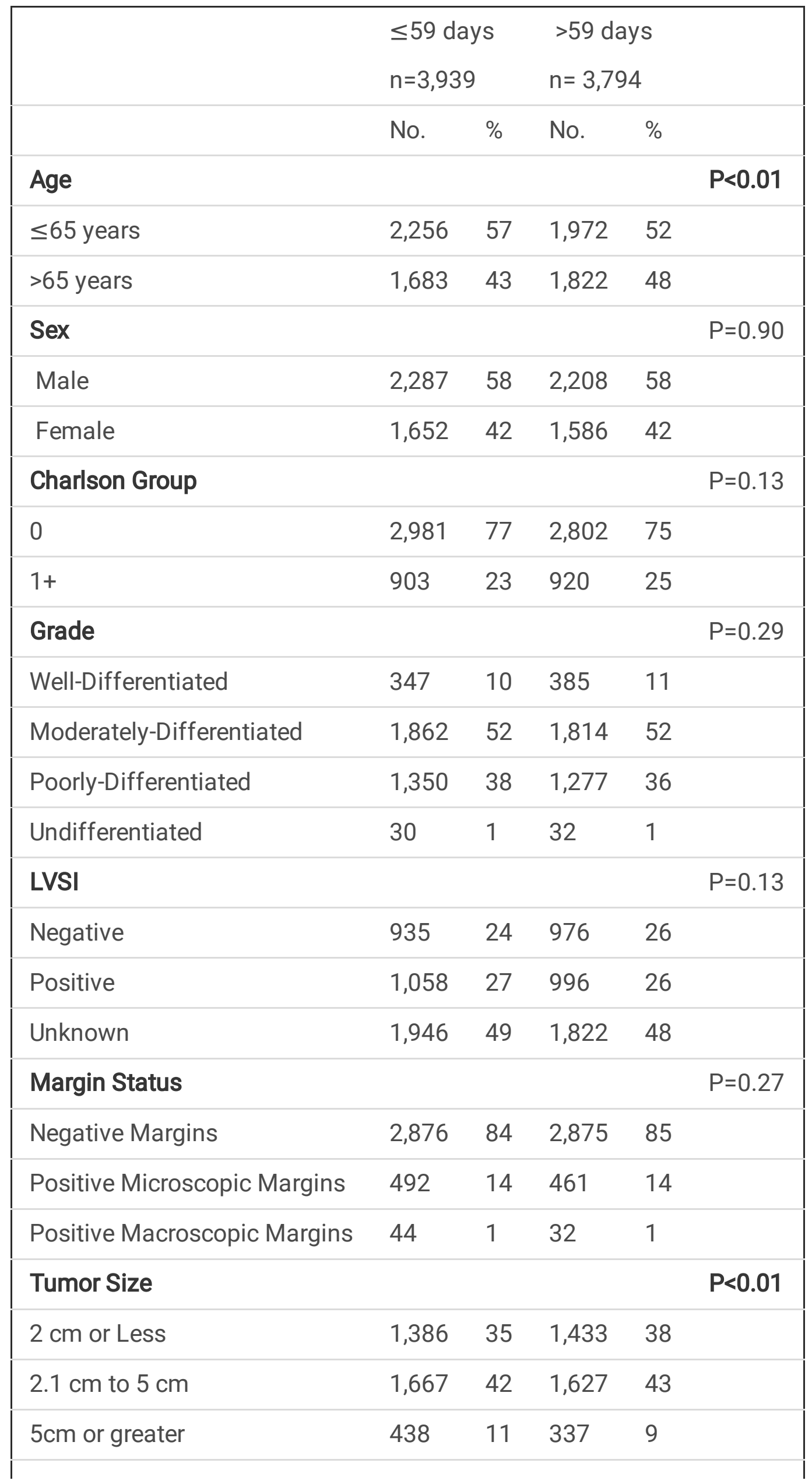




\begin{tabular}{|c|c|c|c|c|c|}
\hline Unknown & 448 & 11 & 397 & 10 & \\
\hline Nodal Status & & & & & $P=0.31$ \\
\hline Node Negative & 1,324 & 48 & 1,304 & 49 & \\
\hline Node Positive & 1,447 & 52 & 1,349 & 51 & \\
\hline Race & & & & & $P=0.03$ \\
\hline White & 3,039 & 78 & 2,845 & 75 & \\
\hline Black & 312 & 8 & 338 & 9 & \\
\hline Hispanic & 293 & 7 & 340 & 9 & \\
\hline Other & 269 & 7 & 251 & 7 & \\
\hline Insurance Status & & & & & $P<0.01$ \\
\hline Private Insurance & 1,866 & 48 & 1,617 & 43 & \\
\hline No Insurance & 107 & 3 & 121 & 3 & \\
\hline Medicaid & 253 & 7 & 267 & 7 & \\
\hline Medicare & 1,649 & 43 & 1,737 & 46 & \\
\hline Income (\$) & & & & & $P=0.56$ \\
\hline Less than 30,000 & 407 & 11 & 411 & 12 & \\
\hline $30,000-34,999$ & 568 & 16 & 537 & 16 & \\
\hline $35,000-45,999$ & 923 & 26 & 923 & 27 & \\
\hline $46,000+$ & 1,677 & 47 & 1,563 & 46 & \\
\hline \multicolumn{5}{|c|}{ Percent of Residents Without a High school Degree } & $P=0.28$ \\
\hline $29 \%+$ & 542 & 15 & 572 & 17 & \\
\hline $20 \%-28.9 \%$ & 754 & 21 & 736 & 21 & \\
\hline $14 \%-19.9 \%$ & 825 & 23 & 786 & 23 & \\
\hline$<14 \%$ & 1,453 & 41 & 1,337 & 39 & \\
\hline \multicolumn{5}{|c|}{ Distance from Treatment Facility } & $P=0.79$ \\
\hline Less than 50 Miles & 3,044 & 82 & 2,934 & 83 & \\
\hline 50 to 200 Miles & 545 & 15 & 512 & 14 & \\
\hline Greater than 200 Miles & 103 & 3 & 91 & 3 & \\
\hline Stage at Diagnosis & & & & & $P=0.12$ \\
\hline
\end{tabular}




\begin{tabular}{|llllll|} 
Stage 1 & 628 & 16 & 637 & 17 & \\
\hline Stage 2 & 1,952 & 50 & 1,927 & 51 & \\
\hline Stage 3 & 1,025 & 26 & 911 & 24 & \\
Unknown & 304 & 8 & 301 & 8 & \\
Treatment Modality & & & & & \\
Radiation alone & 108 & 3 & 175 & 5 & $P<0.01$ \\
Chemotherapy alone & 1,625 & 41 & 1,632 & 43 & \\
Chemoradiation & 2,206 & 56 & 1,987 & 52 & \\
Tumor Location & & & & & $\mathrm{P}=\mathbf{0 . 0 2}$ \\
\hline Intrahepatic & 570 & 14 & 469 & 12 & \\
Extrahepatic & 3,325 & 84 & 3,277 & 86 & \\
\hline Unknown & 44 & 1 & 48 & 1 & \\
\hline
\end{tabular}

Patients who were among the first quartile to initiate adjuvant treatment were compared to those who were not on multivariable analysis (Table 2). Patients in the first quartile to be treated were more likely to have intrahepatic tumors, less likely to be over the age of 65 and less likely to be treated with RT alone than those treated beyond this time point. Similar multivariable analyses were performed for those among the first half of patients to initiate treatment and those in the final quartile (Tables 3 and 4 respectively). Those who initiated treatment in the first half of patients were more likely to have tumors larger than $5 \mathrm{~cm}$ than those who started later. They were less likely to be older than 65 , black or Hispanic, and treated with RT alone. Patients in the final quartile to initiate adjuvant treatment were more likely to be over 65, Hispanic, have Medicaid, have Charlson comorbidity scores of 1 and above, and were more likely to be treated with RT alone. These patients were less likely to have high grade disease than those treated in the first three quartiles.

Table 2. Predictors of initiation of adjuvant therapy within the first quartile of patients ( $\leq 45$ days) assessed by multivariable analysis 


$\begin{array}{lllll}\text { Odds } & \text { Standard } & \text { z- } \\ \text { Ratio } & \text { Error } & \text { score } & \text { P>z } & \begin{array}{l}95 \% \text { Confidence } \\ \text { Interval }\end{array}\end{array}$

\section{Margin Status}

Negative Margins

Reference

Positive Microscopic

$\begin{array}{ll}0.99 & 0.08\end{array}$

$-0.15$

$0.88 \quad 0.84$

1.16

Margins

Positive Macroscopic

0.66

0.17

$-1.64$

0.10

0.40

1.09

Margins

\section{LVSI}

Negative

Reference

Positive

1.02

0.08

0.28

$0.78 \quad 0.87$

1.20

Unknown

0.95

0.07

$-0.74$

$0.46 \quad 0.82$

1.09

\section{Tumor Size}

$2 \mathrm{~cm}$ or Less

\begin{tabular}{lllllll}
$2.1 \mathrm{~cm}$ to $5 \mathrm{~cm}$ & 0.95 & 0.06 & -0.79 & 0.43 & 0.84 & 1.08 \\
\hline $5 \mathrm{~cm}$ or greater & 0.99 & 0.11 & -0.12 & 0.90 & 0.79 & 1.24 \\
\hline Unknown & 0.82 & 0.09 & -1.81 & 0.07 & 0.66 & 1.02
\end{tabular}

\section{Stage at Diagnosis}

Stage 1

Reference

Stage 2

1.08

0.09

0.97

0.33

0.92

1.28

Stage 3

0.96

0.09

$-0.45$

0.65

0.80

1.15

Unknown

1.03

0.14

0.20

0.84

0.79

1.34

\section{Age}

$<=65$ years

Reference

$>65$ years

1.20

0.10

2.27

0.02

1.03

1.41

\section{Treatment Modality}

Radiation alone

Reference

Chemotherapy alone

0.56

0.11

$-2.88$

$\mathbf{0 . 0 0} \quad 0.38$

0.83

Chemoradiation

0.53

0.10

$-3.22$

0.00

0.36

0.78

\section{Insurance Status}

Private Insurance

Reference 


\begin{tabular}{|lllllll|}
\hline No Insurance & 1.23 & 0.22 & 1.17 & 0.24 & 0.87 & 1.73 \\
\hline Medicaid & 1.25 & 0.15 & 1.84 & 0.07 & 0.99 & 1.59 \\
\hline Medicare & 1.14 & 0.10 & 1.60 & 0.11 & 0.97 & 1.34 \\
\hline Race & & & & & & \\
\hline White & Reference & & & & & \\
\hline Black & 1.11 & 0.12 & 0.95 & 0.34 & 0.90 & 1.37 \\
\hline Hispanic & 1.25 & 0.14 & 1.91 & 0.06 & 0.99 & 1.56 \\
\hline Other & 0.98 & 0.11 & -0.17 & 0.87 & 0.78 & 1.23 \\
\hline Tumor Location & & & & & & \\
\hline Intrahepatic & Reference & & & & & \\
\hline Extrahepatic & 1.39 & 0.14 & 3.30 & 0.00 & 1.14 & 1.70 \\
\hline Unknown & 1.85 & 0.60 & 1.92 & 0.06 & 0.99 & 3.48 \\
\hline
\end{tabular}

Table 3. Predictors of initiation of adjuvant therapy within the first half of patients ( $\leq 59$ days) assessed by multivariable analysis 
Odds Ratio Standard Error $\quad z$-score $\quad P>Z \quad 95 \%$ Confidence Interval

\section{Treatment Modality}

\begin{tabular}{lllllll} 
Radiation alone & Reference & & & & \\
Chemotherapy alone & 0.64 & 0.08 & -3.38 & $\mathbf{0 . 0 0}$ & 0.50 & 0.83 \\
Chemoradiation & 0.57 & 0.07 & -4.28 & $\mathbf{0 . 0 0}$ & 0.44 & 0.74 \\
\hline Insurance Status & & & & & &
\end{tabular}

Private Insurance Reference

\begin{tabular}{|c|c|c|c|c|c|c|}
\hline No Insurance & 1.19 & 0.17 & 1.22 & 0.22 & 0.90 & 1.56 \\
\hline Medicaid & 1.16 & 0.11 & 1.52 & 0.13 & 0.96 & 1.40 \\
\hline Medicare & 1.05 & 0.07 & 0.68 & 0.50 & 0.92 & 1.19 \\
\hline \multicolumn{7}{|l|}{ Tumor Size } \\
\hline $2 \mathrm{~cm}$ or Less & \multicolumn{6}{|c|}{ Reference } \\
\hline $2.1 \mathrm{~cm}$ to $5 \mathrm{~cm}$ & 0.96 & 0.05 & -0.80 & 0.42 & 0.87 & 1.06 \\
\hline $5 \mathrm{~cm}$ or greater & 0.81 & 0.08 & -2.27 & 0.02 & 0.68 & 0.97 \\
\hline Unknown & 0.86 & 0.07 & -1.83 & 0.07 & 0.74 & 1.01 \\
\hline \multicolumn{7}{|l|}{ Race } \\
\hline White & \multicolumn{6}{|c|}{ Reference } \\
\hline Black & 1.19 & 0.10 & 2.06 & 0.04 & 1.01 & 1.40 \\
\hline Hispanic & 1.23 & 0.11 & 2.34 & 0.02 & 1.03 & 1.46 \\
\hline Other & 0.99 & 0.09 & -0.12 & 0.90 & 0.82 & 1.19 \\
\hline \multicolumn{7}{|l|}{ Age } \\
\hline$<=65$ years & \multicolumn{6}{|c|}{ Reference } \\
\hline$>65$ years & 1.23 & 0.08 & 3.18 & 0.00 & 1.08 & 1.40 \\
\hline \multicolumn{7}{|l|}{ Tumor Location } \\
\hline Intrahepatic & \multicolumn{6}{|c|}{ Reference } \\
\hline Extrahepatic & 1.12 & 0.09 & 1.53 & 0.13 & 0.97 & 1.30 \\
\hline Unknown & 1.27 & 0.28 & 1.07 & 0.28 & 0.82 & 1.96 \\
\hline
\end{tabular}

Table 4. Predictors of initiation of adjuvant therapy within the final quartile of patients ( $>78$ days) assessed by multivariable analysis 


\begin{tabular}{|c|c|c|c|c|c|c|}
\hline & $\begin{array}{l}\text { Odds } \\
\text { Ratio }\end{array}$ & $\begin{array}{l}\text { Standard } \\
\text { Error }\end{array}$ & $\begin{array}{l}\text { z- } \\
\text { score }\end{array}$ & $P>Z$ & \multicolumn{2}{|c|}{$\begin{array}{l}95 \% \text { Confidence } \\
\text { Interval }\end{array}$} \\
\hline \multicolumn{7}{|l|}{ Charlson Group } \\
\hline 0 & \multicolumn{6}{|c|}{ Reference } \\
\hline $1+$ & 1.19 & 0.10 & 2.09 & 0.04 & 1.01 & 1.40 \\
\hline \multicolumn{7}{|l|}{ Grade } \\
\hline Well-Differentiated & \multicolumn{6}{|c|}{ Reference } \\
\hline $\begin{array}{l}\text { Moderately- } \\
\text { Differentiated }\end{array}$ & 0.75 & 0.09 & -2.39 & 0.02 & 0.60 & 0.95 \\
\hline Poorly-Differentiated & 0.75 & 0.09 & -2.36 & 0.02 & 0.59 & 0.95 \\
\hline Undifferentiated & 0.72 & 0.28 & -0.82 & 0.41 & 0.34 & 1.57 \\
\hline \multicolumn{7}{|l|}{ Treatment Modality } \\
\hline Radiation alone & \multicolumn{6}{|c|}{ Reference } \\
\hline Chemotherapy alone & 0.62 & 0.13 & -2.22 & 0.03 & 0.41 & 0.95 \\
\hline Chemoradiation & 0.54 & 0.12 & -2.86 & $<0.01$ & 0.35 & 0.82 \\
\hline \multicolumn{7}{|c|}{ Percent of Residents Without a High school Degree } \\
\hline $29 \%+$ & \multicolumn{6}{|c|}{ Reference } \\
\hline $20 \%-28.9 \%$ & 0.93 & 0.11 & -0.57 & 0.57 & 0.74 & 1.18 \\
\hline $14 \%-19.9 \%$ & 0.85 & 0.10 & -1.33 & 0.18 & 0.67 & 1.08 \\
\hline$<14 \%$ & 0.94 & 0.10 & -0.59 & 0.56 & 0.75 & 1.17 \\
\hline \multicolumn{7}{|l|}{ Race } \\
\hline White & \multicolumn{6}{|c|}{ Reference } \\
\hline Black & 1.26 & 0.16 & 1.75 & 0.08 & 0.97 & 1.62 \\
\hline Hispanic & 1.56 & 0.20 & 3.39 & $<0.01$ & 1.21 & 2.01 \\
\hline Other & 0.85 & 0.13 & -1.07 & 0.28 & 0.64 & 1.14 \\
\hline \multicolumn{7}{|l|}{ Nodal Status } \\
\hline Node Negative & \multicolumn{6}{|c|}{ Reference } \\
\hline Node Positive & 0.90 & 0.07 & -1.46 & 0.14 & 0.78 & 1.04 \\
\hline \multicolumn{7}{|l|}{ Insurance Status } \\
\hline Private Insurance & Refer & & & & & \\
\hline
\end{tabular}




\begin{tabular}{|lllllll|} 
No Insurance & 1.04 & 0.23 & 0.18 & 0.86 & 0.68 & 1.60 \\
\hline Medicaid & 1.39 & 0.20 & 2.3 & 0.02 & 1.05 & 1.85 \\
\hline Medicare & 1.02 & 0.11 & 0.21 & 0.83 & 0.83 & 1.26 \\
\hline Age & & & & & & \\
\hline$<=65$ years & Reference & & & & & \\
\hline$>65$ years & 1.40 & 0.14 & 3.3 & $<0.01$ & 1.15 & 1.71 \\
\hline
\end{tabular}

After propensity score matching and doubly robust estimation, Charlson scores of 1 or higher, positive LVSI, positive margins, lymph node positivity, tumors larger than $2 \mathrm{~cm}$, age $>65$, high grade disease, and node positivity were prognostic for significantly decreased overall survival in the entire cohort. Income $>\$ 46,000$ and extrahepatic disease site were prognostic for improved survival. There was no association between treatment modality and survival outcomes.Comparing initiation of treatment at various time points, there was no OS difference between patients in the first quartile to initiate adjuvant treatment ( $\leq$ 45 days) and those treated later (HR 0.97, 95\%, Cl 0.87-1.08, $P=.55$ ) (Fig. 2a). However, there was a survival decrement to initiating treatment beyond the median time point of 59 days (HR $1.14,95 \% \mathrm{Cl}$ 1.05-1.25 $P<.01$ ) (Fig. 2b). There was also a survival decrement associated with being amongst the final quartile of patients to initiate treatment (> 78 days) (HR 1.15, 95\% Cl 1.04-1.27, $P=.01)$ (Fig. 2c).

\section{Discussion}

This is a retrospective analysis of the adjuvant treatment of individuals with CCA using a large population database (NCDB). Although CCA is the most common biliary malignancy, it remains rare overall and the data on adjuvant therapy is evolving. Our analysis of a nationwide longitudinal dataset allows for description of care patterns across the US and its territories. This allows for a patterns of care analysis that would not be feasible using single institution or prospective data. We found that a large number of patients did not receive any adjuvant therapy after surgery. Among patients who did receive adjuvant therapy, CRT was the most commonly utilized modality followed by CT alone and RT alone.

The median time to initiation of adjuvant therapy was 59 days, which is largely consistent with the timing requirements on the SWOG and BILCAP studies. ${ }^{12,13}$ We identified a number of patient characteristics that were associated with timing of initiation of adjuvant therapy. Many of these characteristics are consistent with expectation. Age over 65, for example, was associated with delay in initiation of adjuvant therapy, and increased comorbidity score was associated with initiating treatment among the final quartile of patients. Surgical approaches for cholangiocarcinoma vary with location and tumor size, however for most patients it often requires hemi-hepatectomy and bile duct resection. ${ }^{19}$ This is a major surgery with risks of both peri-operative morbidity and mortality. ${ }^{20,21}$ Outcomes have been previously shown to be worse in elderly patients with increased comorbidity, therefore it is unsurprising these patients would be afforded a longer post-operative recovery period. ${ }^{22}$ Larger tumors and higher grade disease were associated with less likelihood of treatment delay; both of these factors have previously 
been shown to have negative impact on outcomes, which may influence providers to be more aggressive initiating adjuvant therapy in these patients. ${ }^{23,}{ }^{24}$ Extrahepatic tumors were more likely to be treated among the first quartile of patients, which may be a result of differences in surgical techniques and associated recovery times between tumor locations. ${ }^{25-27}$

We also identified some predictors of delay that were less expected, including treatment with RT alone as well as black and Hispanic race. As RT alone is not a guideline-supported option for adjuvant therapy, patients treated with RT alone may represent a cohort that is unable to recover adequately from surgery to be treated with CT or CRT. ${ }^{11}$ The finding of black and Hispanic patients having an increased likelihood of treatment delay is a concerning one. While this has not been previously documented in patients with CCA, numerous studies in other malignancies have shown an increased likelihood in therapy delay for minority patients. ${ }^{28,29}$ The explanation for this is complex and multifactorial, with previously explored contributors including decreased access to healthcare resources, distrust in the medical system, language barriers, health literacy, and biases from the medical system. ${ }^{30-32}$ Our findings underscore the continued need for improvements in the equitability of access to timely care for black and Hispanic patients in our medical system.

We identified a number of factors that were associated with decreased OS after propensity score weighting and doubly robust estimation. The majority of these, such as Charlson scores of 1 or higher, positive LVSI, positive margins, lymph node positivity, tumors larger than $2 \mathrm{~cm}$, age $>65$, high grade disease, and node positivity are consistent with previously known prognostic factors in CCA. ${ }^{2,33,34}$

An important novel finding of our study is the finding that delays in initiation beyond the median time point of 59 days were associated with decrements in OS. While this has not been previously described in CCA, there are a number of malignancies in which delay to adjuvant therapy has been shown to be associated with worse outcomes. ${ }^{28,35,36}$ However, in pancreatic ductal adenocarcinoma, the EPSAC-3 showed that completion of chemotherapy rather than early initiation was prognostic, and there was no survival decrement with delay of inititiation up to 12 weeks. ${ }^{37}$ While there are likely a number of patients in whom early initiation of adjuvant therapy is not feasible due to the significant potential morbidity associated with surgery for this disease, these results suggest that timely initiation of adjuvant therapy should be the goal when possible. These findings are especially pertinent in the era of COVID-19 as many cancer therapy patients experience treatment delays. While there may be some patients in whom treatment delay is a reasonable approach for decreasing exposure risk, CCA patients may not be an appropriate group for this mitigation strategy.

This study has several limitations, including those inherent in large database analyses. Confounding bias may have been introduced into this data set because the NCDB does not include information on patient symptoms, specific comorbid conditions or palliative interventions. To address the possibility of known confounders, we performed propensity score-matching by IPTW and doubly-robust estimation, which can significantly reduce selection bias. ${ }^{38,39}$ However, it is difficult to control for all unknown confounders 
outside of a setting of a randomized clinical trial. It is possible, therefore, that factors such as disease biology, which we are unable to control for, may be associated with delays in therapy and influence our results. Additionally, we are unable to evaluate local recurrence or disease specific survival as these outcomes are not recorded in the NCDB. Thus, this data set could not be analyzed for these outcomes, nor determine whether disease control was associated with overall survival in our patient cohort. Finally, we did not have any information regarding the morbidity associated with surgery which may contribute to both timing of adjuvant therapy survival outcomes. Due to these limitations, these findings are hypothesis generating and require further study to confirm the findings.

\section{Conclusions}

This is the first study to evaluate the impact of timing of adjuvant therapy in patients with resected CCA. We identified characteristics that are related to the timing of adjuvant therapy in these patients. Black and Hispanic patients were more likely to experience a delay in adjuvant therapy and there is a need for improved equitable access to heathcare resources for these CCA patients. There was an OS decrement associated with delays beyond the median time point of 59 days. Our findings may be especially relevant given the treatment delays seen for cancer patients as a result of COVID-19 and to heighten awareness on treatment delays for vulnerable populations.

\section{Declarations}

- Funding: None

- Disclosure: The authors declare they have no conflicts of interest.

- Availability of data and material: The datasets generated during and/or analysed during the current study are available from the corresponding author on reasonable request.

- Code Availability: The custom code created for analysis of the data is available from the corresponding author on reasonable request.

\section{Author Contributions:}

MP and RT conceived and designed the research.

MP conducted the data analysis and wrote the manuscript.

All authors read, edited, and approved the manuscript.

\section{References}

1. Rizvi S, Gores GJ. Pathogenesis, diagnosis, and management of cholangiocarcinoma. Gastroenterology Dec. 2013;145(6):1215-29. doi:10.1053/j.gastro.2013.10.013. 
2. Rizvi S, Khan SA, Hallemeier CL, Kelley RK, Gores GJ. Cholangiocarcinoma - evolving concepts and therapeutic strategies. Nat Rev Clin Oncol Feb. 2018;15(2):95-111. doi:10.1038/nrclinonc.2017.157.

3. Banales JM, Marin JJG, Lamarca A, et al. Cholangiocarcinoma 2020: the next horizon in mechanisms and management. Nat Rev Gastroenterol Hepatol Sep. 2020;17(9):557-88. doi:10.1038/s41575-020-0310-z.

4. Saha SK, Zhu AX, Fuchs CS, Brooks GA. Forty-Year Trends in Cholangiocarcinoma Incidence in the U.S.: Intrahepatic Disease on the Rise. Oncologist May. 2016;21(5):594-9. doi:10.1634/theoncologist.2015-0446.

5. Blechacz B, Komuta M, Roskams T, Gores GJ. Clinical diagnosis and staging of cholangiocarcinoma. Nat Rev Gastroenterol Hepatol Aug. 2011;2(9):512-22. doi:10.1038/nrgastro.2011.131. 8 ) .

6. Valle JW, Lamarca A, Goyal L, Barriuso J, Zhu AX. New Horizons for Precision Medicine in Biliary Tract Cancers. Cancer Discov Sep. 2017;7(9):943-62. doi:10.1158/2159-8290.CD-17-0245.

7. Jarnagin WR, Fong Y, DeMatteo RP, et al. Staging, resectability, and outcome in 225 patients with hilar cholangiocarcinoma. Ann Surg Oct. 2001;234(4):507-17. doi:10.1097/00000658-20011000000010. discussion 517-9.

8. Blechacz B. Tumors of the Bile Ducts, Gallbladder, and Ampulla. Feldman: Sleisenger and Fordtran's Gastrointestinal and Liver Disease. Saunders; 2010:1171-1176.

9. Doherty B, Nambudiri VE, Palmer WC. Update on the Diagnosis and Treatment of Cholangiocarcinoma. Curr Gastroenterol Rep Jan. 2017;19(1):2. doi:10.1007/s11894-017-0542-4.

10. Benson AB, D'Angelica MI, Abbott DE, et al. Guidelines Insights: Hepatobiliary Cancers, Version 2.2019. J Natl Compr Canc Netw Apr. 2019;1(4):302-10. doi:10.6004/jnccn.2019.0019. 17 ) .

11. (NCCN) NCCN. Hepatobiliary Cancers Version 5.2020. Updated August 4. 2020. Accessed 2/9/21, 2021. https://www.nccn.org/professionals/physician_gls/pdf/hepatobiliary.pdf.

12. Ben-Josef E, Guthrie KA, El-Khoueiry AB, et al. SWOG S0809: A Phase II Intergroup Trial of Adjuvant Capecitabine and Gemcitabine Followed by Radiotherapy and Concurrent Capecitabine in Extrahepatic Cholangiocarcinoma and Gallbladder Carcinoma. J Clin Oncol Aug. 2015;20(24):261722. doi:10.1200/JCO.2014.60.2219. 33 ) .

13. Primrose JN, Fox RP, Palmer DH, et al. Capecitabine compared with observation in resected biliary tract cancer (BILCAP): a randomised, controlled, multicentre, phase 3 study. Lancet Onco/ May. 2019;20(5):663-73. doi:10.1016/S1470-2045(18)30915-X.

14. Patt D, Gordan L, Diaz M, et al. Impact of COVID-19 on Cancer Care: How the Pandemic Is Delaying Cancer Diagnosis and Treatment for American Seniors. JCO Clin Cancer Inform Nov. 2020;4:105971. doi:10.1200/CCI.20.00134.

15. Akula SM, Abrams SL, Steelman LS, et al. Cancer therapy and treatments during COVID-19 era. Adv Biol Regul Aug. 2020;77:100739. doi:10.1016/j.jbior.2020.100739.

16. Kutikov A, Weinberg DS, Edelman MJ, Horwitz EM, Uzzo RG, Fisher RI. A War on Two Fronts: Cancer Care in the Time of COVID-19. Ann Intern Med Jun. 2020;2(11):756-8. doi:10.7326/M20-1133. 172) 
17. Bilimoria KY, Stewart AK, Winchester DP, Ko CY. The National Cancer Data Base: a powerful initiative to improve cancer care in the United States. Ann Surg Oncol Mar. 2008;15(3):683-90. doi:10.1245/s10434-007-9747-3.

18. STATA/IC-14. Version Version Release 14. StataCorp, LP; 2015.

19. Cillo U, Fondevila C, Donadon M, et al. Surgery for cholangiocarcinoma. Liver Int May. 2019;39(Suppl 1):143-55. doi:10.1111/liv.14089.

20. Nuzzo G, Giuliante F, Ardito F, et al. Improvement in perioperative and long-term outcome after surgical treatment of hilar cholangiocarcinoma: results of an Italian multicenter analysis of 440 patients. Arch Surg Jan. 2012;147(1):26-34. doi:10.1001/archsurg.2011.771.

21. Wiggers JK, Groot Koerkamp B, Cieslak KP, et al. Postoperative Mortality after Liver Resection for Perihilar Cholangiocarcinoma: Development of a Risk Score and Importance of Biliary Drainage of the Future Liver Remnant. J Am Coll Surg Aug. 2016;223(2):321-31 e1. doi:10.1016/j.jamcollsurg.2016.03.035.

22. Tzeng CW, Cooper AB, Vauthey JN, Curley SA, Aloia TA. Predictors of morbidity and mortality after hepatectomy in elderly patients: analysis of 7621 NSQIP patients. HPB (Oxford) May. 2014;16(5):459-68. doi:10.1111/hpb.12155.

23. Martin SP, Ruff S, Diggs LP, et al. Tumor grade and sex should influence the utilization of portal lymphadenectomy for early stage intrahepatic cholangiocarcinoma. HPB (Oxford) Apr. 2019;21(4):419-24. doi:10.1016/j.hpb.2018.07.026.

24. Bagante F, Spolverato G, Merath K, et al. Intrahepatic cholangiocarcinoma tumor burden: A classification and regression tree model to define prognostic groups after resection. Surgery Dec. 2019;166(6):983-90. doi:10.1016/j.surg.2019.06.005.

25. Beal EW, Cloyd JM, Pawlik TM. Surgical Treatment of Intrahepatic Cholangiocarcinoma: Current and Emerging Principles. J Clin Med Dec 30 2020;10(1)doi:10.3390/jcm10010104.

26. Cipriani F, Ratti F, Fiorentini G, Reineke R, Aldrighetti L. Systematic review of perioperative and oncologic outcomes of minimally-invasive surgery for hilar cholangiocarcinoma. Updates Surg Feb 22 2021;doi:10.1007/s13304-021-01006-6.

27. Jikei K, Ebata T, Mizuno T, et al. Oncologic Reappraisal of Bile Duct Resection for Middle-Third Cholangiocarcinoma. Ann Surg Oncol Sep 22 2020;doi:10.1245/s10434-020-09157-3.

28. Chavez-MacGregor M, Clarke CA, Lichtensztajn DY, Giordano SH. Delayed Initiation of Adjuvant Chemotherapy Among Patients With Breast Cancer. JAMA Onco/ Mar. 2016;2(3):322-9. doi:10.1001/jamaoncol.2015.3856.

29. Fedewa SA, Edge SB, Stewart AK, Halpern MT, Marlow NM, Ward EM. Race and ethnicity are associated with delays in breast cancer treatment (2003-2006). $J$ Health Care Poor Underserved Feb. 2011;22(1):128-41. doi:10.1353/hpu.2011.0006.

30. Levy H, Janke A. Health Literacy and Access to Care. J Health Commun. 2016;21(Suppl 1):43-50. doi:10.1080/10810730.2015.1131776. 
31. Halbert CH, Armstrong K, Gandy OH Jr, Shaker L. Racial differences in trust in health care providers. Arch Intern Med Apr. 2006;24(8):896-901. doi:10.1001/archinte.166.8.896. 166 ) .

32. Davis TC, Williams MV, Marin E, Parker RM, Glass J. Health literacy and cancer communication. $C A$ Cancer J Clin May-Jun. 2002;52(3):134-49. doi:10.3322/canjclin.52.3.134.

33. Wang Y, Li J, Xia Y, et al. Prognostic nomogram for intrahepatic cholangiocarcinoma after partial hepatectomy. J Clin Onco/ Mar. 2013;20(9):1188-95. doi:10.1200/JC0.2012.41.5984. 31 ) .

34. Aktas G, Kus T, Balkan A, Metin T, Gulsen MT, Abali H. Prognostic factors in patients with advanced extrahepatic cholangiocarcinoma: A single center experience. Medicine (Baltimore) Feb. 2019;98(8):e14556. doi:10.1097/MD.0000000000014556.

35. Thong DW, Kim J, Naik A, Lu CT, Nolan GJ, Von Papen M. Delay to Adjuvant Chemotherapy: Survival and Recurrence in Patients of Rectal Cancer Treated with Neo-adjuvant Chemoradiotherapy and Surgery. J Gastrointest Cancer Sep. 2020;51(3):877-86. doi:10.1007/s12029-019-00312-y.

36. McMillan MT, Ojerholm E, Roses RE, et al. Adjuvant Radiation Therapy Treatment Time Impacts Overall Survival in Gastric Cancer. Int J Radiat Oncol Biol Phys Oct. 2015;1(2):326-36. doi:10.1016/j.ijrobp.2015.05.025. 93 ) .

37. Valle JW, Palmer D, Jackson R, et al. Optimal duration and timing of adjuvant chemotherapy after definitive surgery for ductal adenocarcinoma of the pancreas: ongoing lessons from the ESPAC-3 study. J Clin Oncol Feb. 2014;20(6):504-12. doi:10.1200/JC0.2013.50.7657. 32 ) .

38. Funk MJ, Westreich D, Wiesen C, Sturmer T, Brookhart MA, Davidian M. Doubly robust estimation of causal effects. Am J Epidemiol Apr. 2011;1(7):761-7. doi:10.1093/aje/kwq439. 173 ) .

39. Austin PC. An Introduction to Propensity Score Methods for Reducing the Effects of Confounding in Observational Studies. Multivariate Behav Res May. 2011;46(3):399-424. doi:10.1080/00273171.2011.568786.

\section{Figures}




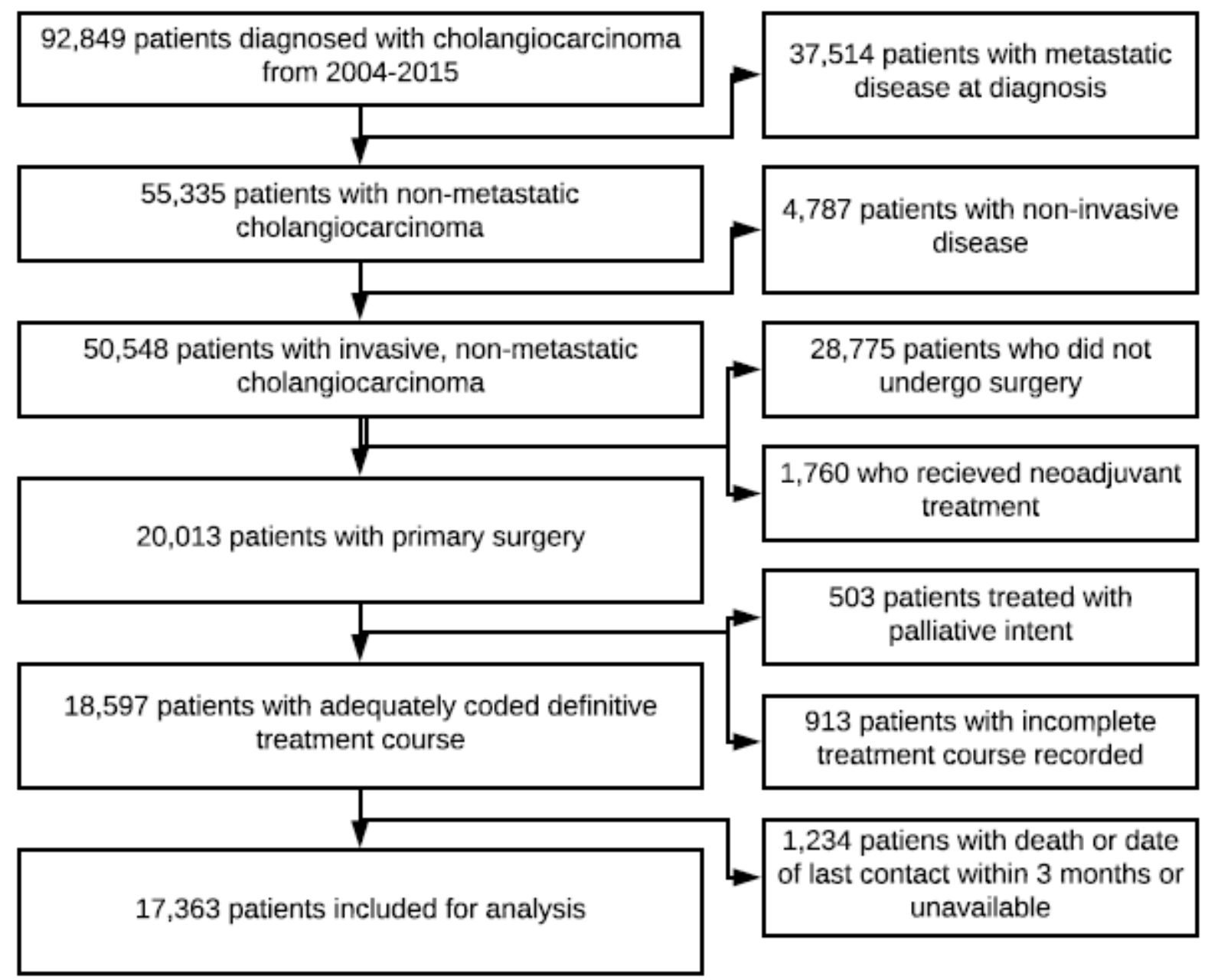

\section{Figure 1}

Flow chart of patient selection. Patients with non-metastatic cholangiocarcinoma who underwent surgical resection were selected. Those who had metastatic disease, in-situ lesions, received neoadjuvant or palliative treatments, or who did not undergo surgery were excluded

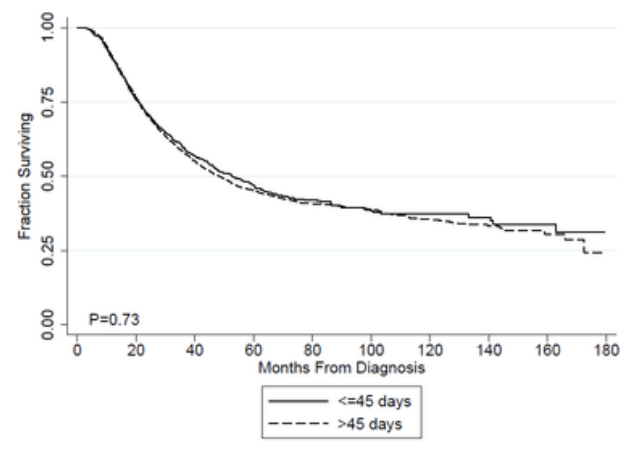

A

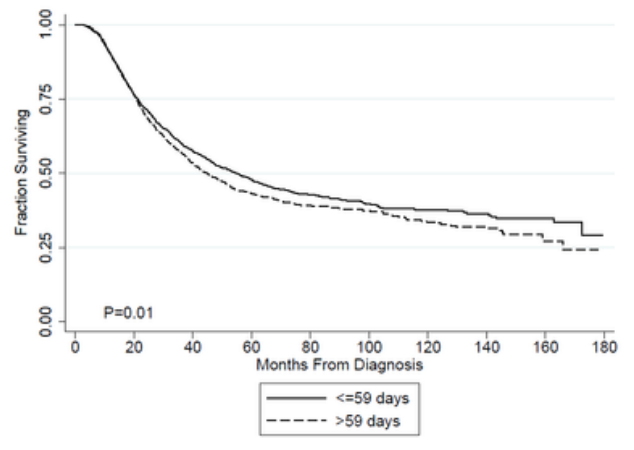

B

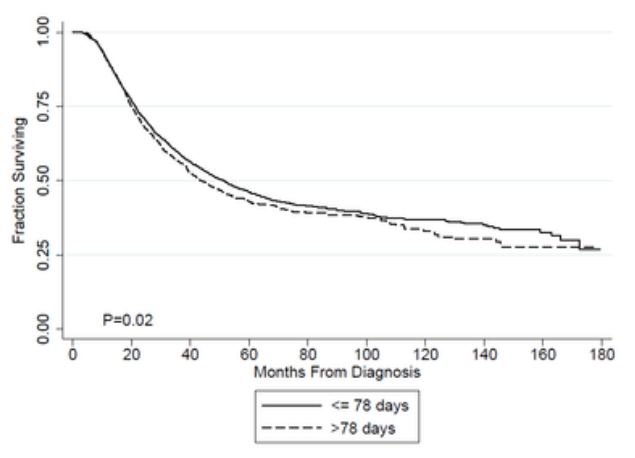

C

Figure 2

Fifteen-year overall survival for patients who were treated before and after various time points. Data are shown for (a) patients treated before and after 45 days (the first quartile), (b) patients treated before and 
after 59 days (the median), (c) patients treated before and after 78 days (the final quartile) 